\title{
Acta
Biochimica
Polonica
}

Vol. 47 No. 2/2000

$281-292$

QUARTERLY

\section{Antioxidant defense in centenarians (a preliminary study)}

\author{
Barbara Kłapcińska ${ }^{1}$, Jarosław Derejczyk ${ }^{2}$, Katarzyna Wieczorowska-Tobis ${ }^{3}$, Andrzej \\ Sobczak $^{4}$, Ewa Sadowska-Krępa ${ }^{1}$ and Alojzy Danch ${ }^{4}$ \\ ${ }^{1}$ Academy of Physical Education, Katowice, ${ }^{2}$ Geriatric Hospital, Katowice, ${ }^{3}$ Medical Academy, \\ Poznań, ${ }^{4}$ Silesian Medical University, Katowice, Poland
}

Received: 31 January, 2000

Key words: centenarians, antioxidant enzymes, blood

\begin{abstract}
The study was designed to assess the antioxidant defense mechanisms, either enzymatic or non-enzymatic, in a group of sixteen centenarians (one male and fifteen female subjects aged 101 to 105 years) living in the Upper Silesia district (Poland) in order to evaluate the potential role of antioxidant defenses in human longevity. The results of our preliminary study showed that in comparison with young healthy female adults the centenarians had significantly higher red blood cell glutathione reductase and catalase activities and higher, although insignificantly, serum vitamin $\mathrm{E}$ level.
\end{abstract}

The network theory of aging postulates the existence of a variety of cellular defense mechanisms enabling to maintain a balance between the processes favouring and counteracting senescence. Among these interconnected and integrated cellular defense systems is the mechanism of antioxidant defense (Franceschi et al., 1992). Free radical theory of aging, first presented by Harman (1992), implies that aging changes are caused by free radical reactions leading to oxidative damage of multiple cellular components. A statistically significant inverse correlation was found between a spontaneous autooxidation of aerobically incubated tissue homogenates of many different mammalian species and their maximum lifespan potential. Human tissues appeared to have unusually low sensitivity to autooxidation, most likely due to their relatively high antioxidant defense capacity (Cut-

\footnotetext{
${ }^{\circledR}$ Corresponding author: Barbara Kłapcińska, Department of Physiological and Medical Sciences, Biochemistry Unit, Academy of Physical Education, Mikołowska 72A, 40-065 Katowice (Poland); tel/fax: (48 32) 251 6868; tel: (48 32) 207 7158; e-mail: barbara@awf.katowice.pl

Abbreviations: AGE, advanced glycation end products; BHT, butylated hydroxytoluene; BMI, body mass index; CAT, catalase; EGRAC, erythrocyte glutathione reductase activity coefficient; GR, glutathione reductase; GSH-Px, glutathione peroxidase; Hct, hematocrit; MDA, malondialdehyde; MMSE, mini-mental state examination; RBC, red blood cell; SA, sinoatrial; SOD, superoxide dismutase; SVPB; supraventicular premature beats; TBA, thiobarbituric acid; WBC, white blood cell.
} 
ler, 1985). These findings encouraged numerous researchers to undertake studies on the contribution of peroxidation defense processes to human longevity.

Our study aimed at the evaluation of the antioxidant defense mechanisms, either enzymatic or non-enzymatic, in centenarians living in the Upper Silesia district (Poland), as an attempt to appraise the potential role of these mechanisms in human aging.

\section{METHODS}

Subjects. Sixteen centenarians (15 females and 1 male), aged from 101 to 105 years, gave their consent to be examined within this study. The medical examination by a physician (specialist in geriatry) included evaluation of functional health, 12-lead electrocar- diogram (ECG) record and taking measures of body mass and height to assess Body Mass In$\operatorname{dex}(\mathrm{BMI})$. The subjects were then asked to answer a questionnaire specially elaborated for this study (Mini-Mental State Examination, MMSE). They were also supposed to answer questions dealing with their previous and actual nutritional habits, state of health, physical activity, life-span of their close relatives and other general questions that enable to evaluate their cognitive function, coping behaviour and social integration. The final MMSE score < 24 was interpreted as indicating a certain degree of impairment of cognitive function. The characteristics of the subjects is presented in Table 1 .

As the analyses of blood samples for the activities of antioxidant enzymes and low molecular mass antioxidants were performed only for twelve female centenarian subjects and

Table 1. Basic characteristics of subjects

\begin{tabular}{llllccl}
\hline Initials & Gender & Age & BMI & MMSE & Level of physical activity* & Cardiac rhythm \\
\hline JN & F & 105 & 29.5 & 24 & B & sinus \\
KK & F & 103 & 19.8 & 21 & B & sinus \\
PS & F & 103 & 27 & 17 & B & sinus \\
WA & F & 102 & 20 & 8 & A & atrial fibrillation \\
WB & F & 102 & 18.6 & 8 & A & sinus \\
UA & F & 102 & 27.5 & 18 & sinus \\
HA & F & 102 & 30.2 & 30 & B & sinus \\
BA & F & 102 & 18.2 & 21 & sinus \\
LE & F & 102 & 21.8 & 2 & A & atrial fibrillation \\
GJ & F & 101 & 23 & 21 & B & sinus \\
JW & F & 101 & 15.1 & 11 & A & sinus \\
MM & F & 101 & 20.5 & 19 & A & sinus \\
DM & F & 101 & 33.2 & 0 & A & sinus \\
MJ & M & 101 & 23.8 & 12 & B & sinus \\
SM & F & 101 & 19.5 & 3 & A & SVPBs \\
JZ & F & 101 & 20.1 & 30 & B & sinus \\
\hline Mean & & 101.9 & 23.15 & 15.3 & & \\
\pm S.D. & & 1.1 & 5.21 & 9.4 & 16 & \\
$\mathrm{n}$ & & 16 & 16 & & & \\
\hline
\end{tabular}

*Physical activity: A, bedridden but able to sit on the bed; B, unable to go outside without help; C, free living; ${ }^{* *}$ SVPBs, supraventricular premature beats. 
the reference range for the parameters of the antioxidant defense system is still lacking, a group of 9 young healthy females aged 20 to 22 years volunteered to give their blood samples in order to assess the antioxidant status in young female adults as reference.

Analytical methods. Blood for biochemical assays was withdrawn from the antecubital vein after an overnight fast. Blood hemoglobin concentration $(\mathrm{Hb})$, hematocrit values (Hct), red blood cell count (RBC), and white blood cell count (WBC) were determined by standard procedures. In whole blood samples the activity of glutathione peroxidase (GSHPx; EC 1.11.1.9) was assessed by the method of Flohe \& Gunzler (1984) with t-butyl hydroperoxide as substrate. The concentration of selenium in whole blood was determined spectrofluorometrically according to Danch \& Dróżdż (1996) with 2,3-diaminonaphtalene used as complexing agent. In hemolysates of red blood cells the activity of catalase (CAT; EC 1.11.1.6) was determined according to Aebi (1974), that of superoxide dismutase (SOD; EC 1.15.1.1) by using commercial RANSOD kits (Randox, England) and glutathione reductase (GR; EC 1.6.4.2) activity by the method of Glatzle et al. (1970). The activities of antioxidant enzymes were expressed per gram of hemoglobin. In plasma samples uric acid and glucose concentrations were assessed by using commercial kits (Analco, Poland), vitamin E by HPLC (Sobczak et al., 1999) and reaction products of malondialdehyde (MDA) with thiobarbituric acid (TBA) by the method of Buege-Aust (1978) with extraction of chromogen with n-butanol and addition of butylated hydroxytoluene (BHT $-0,01 \%)$ to the TBA reagent to lower the metal-catalysed autooxidation of lipids. In serum the advanced glycation end products (AGEs) concentration was determined by ELISA (Papanastasiou et al., 1994), homocysteine by HPLC (Young et $a l ., 1994)$ and that of insulin by immunoradiometric (IRA) method (Casesnoves et al., 1998).

\section{RESULTS AND DISCUSSION}

Medical examination of our centenarians, which included 12-lead electrocardiogram record, revealed that a majority of them (13 out of 16 subjects) had normal sinus rhythm of the heart - this means that the heartbeat was paced by the normal pacemaker - the sinoatrial (SA) node. Only in one subject supraventricular premature beats (SVPBs) were observed and in two other - atrial fibrillation was diagnosed (Table 1). The normal heart rhythm enables a proper supply of oxygen to all tissues, thus preventing ischemia of the brain and the apoptotic death of neuron cells, one of the major factors implicated in development of senile dementia. Moreover, rhythm disturbances can play role in enhancement of oxidative stress developed in the ischemic reperfused myocardium, which, as it was revealed by Maulik et al. (1998), induces apoptotic cell death. It is worthy to note that in the case of atrial fibrillation the supply of blood (and thus oxygen) is diminished by about $30 \%$. This might be one of the causal factors responsible for low cognitive function and very low MMSE score evidenced in our subjects with arrhythmias. There was only one exception of a patient with normal sinus rhythm and nul MMSE score, but it seems likely that in this case a very low cognitive function could be attributed to the state of total blindness acquired late in the patient's life.

Our findings seem to be in agreement with those of Roberts (1998), who reported that none of 6 patients aged 100 to 103 years had apparent clinical evidence of myocardial ischemia or congestive heart failure during life, and those of Cobler et al. (1989) who found that ischemic heart disease as an underlying pathology necessitating pacemaker implantation was rare in centenarians.

The hematological and selected biochemical parameters in our subjects are presented in Table 2. Levels of hemoglobin, hematocrit, RBC, WBC and white blood cell morphology (not shown) were within the reference range 
for adults (Jakubowski et al., 1995). Our results do not support the contrary observation of Caprari et al. (1999) of a significant decrease in $\mathrm{RBC}, \mathrm{Hb}$ and Hct in centenarians; it seems that origin of this discrepancy might be a more advanced age (103 years) and possibly worse nutritional status of their subjects.

The parameters that characterize enzymatic and non-enzymatic antioxidant defenses are presented in Tables 3 and 4 for centenarian and young female adult subjects, respectively. As to antioxidant enzymes, characteristic was a lower ( $P<0.05$ by Mann-Whitney U-test) activity of superoxide dismutase in centenari-
Well documented is the view that the level of oxidative stress increases with advancing age, but it is still not clear whether it is due to a decline of antioxidant defense system capacity or an increase in the rate of prooxidant production. Data from the literature obtained from studies on different animal species are not consistent. An age-related decline in SOD activity was observed by Sohal \& Orr (1992) in housefly as well as in liver and heart of Sprague-Dawley rats but not in Drosophila. Interestingly, these authors did not found any clear association between the enzymatic antioxidant defense in six different mammalian

Table 2. Selected hematological and biochemical parameters in centenarians

\begin{tabular}{|c|c|c|c|c|c|c|c|}
\hline Initials & $\begin{array}{c}\mathrm{Hb} \\
(\mathrm{g} / \mathrm{dL})\end{array}$ & $\begin{array}{l}\text { Hct } \\
(\%)\end{array}$ & $\begin{array}{c}\mathrm{WBC}_{3} \\
\left(1 / \mu \mathrm{m}^{3}\right)\end{array}$ & $\left(10^{\mathrm{B}} / \mu \mathrm{m}^{3}\right)$ & $\begin{array}{l}\text { Glucose } \\
\text { (mg/dL) }\end{array}$ & $\underset{\text { (mIU/L) }}{\text { Insulin }}$ & $\begin{array}{l}\text { AGE-s } \\
(\mathrm{U} / \mathrm{L})\end{array}$ \\
\hline $\mathrm{JN}$ & 15.00 & 41 & 7500 & 4.305 & 119 & 10.4 & 14.22 \\
\hline KK & 15.20 & 40 & 7900 & 4.200 & 138 & 1.1 & 3.25 \\
\hline PS & 15.19 & 44 & 8000 & 4.620 & 92 & 3.3 & 14.36 \\
\hline WA & ND & ND & ND & ND & 90 & 0.2 & 24.58 \\
\hline WB & 15.57 & 43 & 8000 & 4.515 & 88 & 0.3 & 14.29 \\
\hline UA & 12.92 & 36 & 7400 & 3.780 & 92 & 2.4 & 18.79 \\
\hline HA & 15.29 & 42 & 8200 & 4.410 & 92 & 6.5 & 3.12 \\
\hline BA & 14.42 & 38 & 7300 & 3.990 & 121 & 4.6 & 14.58 \\
\hline LE & 14.20 & 40 & 7950 & 4.200 & 107 & 49.3 & 31.09 \\
\hline GJ & 11.87 & 33 & 7100 & 3.465 & 203 & 21.65 & 26.84 \\
\hline JW & 14.35 & 42 & 7900 & 4.410 & 104 & 30.3 & 49.50 \\
\hline MM & 14.97 & 43 & 7500 & 4.515 & ND & ND & ND \\
\hline $\mathrm{DM}$ & ND & ND & ND & ND & 118 & 24.3 & 15.10 \\
\hline MJ & ND & ND & ND & ND & 72 & 6.91 & 8.70 \\
\hline $\mathrm{SM}$ & ND & ND & ND & ND & 98 & 2.6 & ND \\
\hline $\mathrm{JZ}$ & ND & ND & ND & ND & 72 & 6.9 & 27.48 \\
\hline Mean & 14.44 & 40.3 & 7704 & 4.22 & 107.9 & 11.3 & 19.7 \\
\hline S.D. & 1.11 & 3.3 & 355 & 0.35 & 31.3 & 14.1 & 11.9 \\
\hline $\mathrm{n}$ & 11 & 11 & 11 & 11 & 15 & 15 & 13 \\
\hline
\end{tabular}

ans as compared with young healthy female subjects (716.9 vs $872.6 \mathrm{U} / \mathrm{g} \mathrm{Hb}$, respectively), whereas the catalase activity was higher ( $P<0.05$ by Mann-Whitney U-test) in centenarians (245.9 vs 198.4 k/g Hb, respectively). species and their maximum life span potential. Therefore, their suggestion is that the major factor implicated in the age-related increase in oxidative stress is the enhanced rate of mitochondrial superoxide radicals $\mathrm{O}_{2}{ }^{\cdot-}$ 
and hydrogen peroxide $\left(\mathrm{H}_{2} \mathrm{O}_{2}\right)$ generation. There are many reports from animal experiments which evidenced the age-related increase in activity of antioxidant enzymes (Fielding \& Meydani,1997; Sohal \& Orr, 1992). Less conclusive are results of human studies on aging and oxidative stress. Some authors underly the anti-aging action of dietary restriction being an effective modulator of oxidative stress (Yu, 1996) or dietary supplementation with antioxidants (Cao et al., 1998). However, almost two decades of research on correlation between superoxide dismutase activity and aging or life span, either in animals or humans, failed to elucidate the role of SOD in aging (Warner, 1994). It seems likely that a compensatory balance exists among various components that contribute to the overall antioxidant defense system in tissues and blood.

Table 3. Selected parameters of the antioxidant defense system in young female subjects aged 20 to 22 years

\begin{tabular}{lcc}
\hline Parameter & Mean & \multicolumn{1}{c}{ S.D. } \\
\hline SOD, U/g Hb & 872.6 & 151.2 \\
CAT, $k / \mathrm{g} \mathrm{Hb}$ & 198.4 & 39.5 \\
GSH-Px, U/g Hb & 18.39 & 5.81 \\
GR, U/g Hb & 16.73 & 3.35 \\
MDA, $\mu$ mol/L & 4.45 & 1.73 \\
Se, $\mu$ g/L & 54.48 & 8.34 \\
$\alpha$-Tocopherol, mg/L & 11.59 & 2.11 \\
Uric acid, mg/dL & 3.46 & 0.95 \\
\hline
\end{tabular}

In this respect interesting seems the effect of aging on the erythrocyte glutathione system, especially the activity of glutathione reductase (GR) and glutathione peroxidase (GSH$\mathrm{Px}$ ). Glutathione peroxidase activity in centenarians appeared to be very close to the values found in young female subjects, although selenium concentration in whole blood was lower in the aged group $(37.3 \pm 15.7 \mu \mathrm{g} / \mathrm{L})$ as compared to young female subjects $(54.5 \pm 8.3$ $\mu \mathrm{g} / \mathrm{L}$ ) (Tables 3 and 4), the difference was not significant. A decline in blood selenium concentration with age was also observed by other authors (Olivieri et al.,1994). Comparable values of GSH-Px activity in centenarians and young adults, independent of differences in selenium levels, may be interpreted in the same terms as in the case of very young infants, having lower selenium level than older children but similar GSH-Px activity (Lombeck et al., 1977).

Glutathione reductase activity in centenarians was significantly higher $(P<0.05$ by Mann-Whitney U-test) as compared to the values found in female adults (Tables 3 and 4). Our observations are in a good agreement with those reported by Rodriguez-Martinez \& Ruiz-Torres (1992), Rodriguez et al. (1996) and Toh et al. (1994). Rodriguez-Martinez \& Ruiz-Torres (1992) reported a clear glutathione reductase increase with age, which they interpreted as a positive feedback mechanism in response to rising lipid peroxidation. It is worth to underly that Lopez-Torres et al. (1993) revealed, in an animal model, that simultaneous induction of superoxide dismutase, glutathione, vitamin $\mathrm{C}$ and especially glutathione reductase could increase the mean life-span of vertebrate animal.

A determination of glutathione reductase (GR) activity may also be useful in assessement of the riboflavin status. Erythrocyte glutathione reductase activity coefficient (EGRAC), which is a functional test indicative of metabolic availability of riboflavin, could be determined by measuring GR activity in the absence and then in the presence of FAD (Glatzle et al., 1970). According to the frequently used criterion that an EGRAC value $\geq 1.20$ is indicative of inadequate vitamin $\mathrm{B}_{2}$ status, we found that only two our subjects showed riboflavin deficiency.

We may presume that the increase in the activities of antioxidant enzymes in blood of our subjects, mainly glutathione reductase and catalase (to a lesser extent), could be interpreted as favorable response of the organism 
to oxidative stress which enables to maintain the balance between the production of reactive oxygen species (ROS) and efficacy of antioxidant defenses in normal aging. Here, it is worthy to recall interesting results of recent research of glutamate toxicity (via enhanced accumulation of ROS which leads to apoptotic cell death) on HT-22 mouse nerve cell subclones extremely resistant to ROS, in pattern. A similar trend was found in centenarians examined in our study.

There is a common view that vitamin $\mathrm{E}$ compounds (tocopherols) can retard the aging process. Vitamin $\mathrm{E}$ is considered as the only lipid-soluble, chain-breaking type of antioxidant present in human blood. It appears in plasma and platelets mainly in two forms as $\alpha$ and $\gamma$-tocopherol, the mean $\gamma$-tocopherol con-

Table 4. Activity of antioxidant enzymes in whole blood (GSH-Px) and erythrocytes (SOD, CAT, GR) of centenarians

\begin{tabular}{lcccccc}
\hline Initials & $\begin{array}{c}\text { SOD } \\
(\mathrm{U} / \mathrm{gHb})\end{array}$ & $\begin{array}{c}\mathrm{CAT} \\
(k / \mathrm{gHb})\end{array}$ & $\begin{array}{c}\text { GSH-Px } \\
(\mathrm{U} / \mathrm{gHb})\end{array}$ & $\begin{array}{c}\text { GR }(-\mathrm{FAD}) \\
(\mathrm{U} / \mathrm{gHb})\end{array}$ & $\begin{array}{c}\text { GR (+FAD) } \\
(\mathrm{U} / \mathrm{gHb})\end{array}$ & EGRAC* $^{*}$ \\
\hline JN & 674.5 & 237.2 & 14.59 & 48.39 & 61.14 & 0.790 \\
KK & 614.9 & 216.7 & 17.70 & 34.46 & 41.24 & 0.835 \\
PS & 677.7 & 203.0 & 25.91 & 37.16 & 48.02 & 0.774 \\
WA & 735.5 & 194.6 & $\mathrm{ND}$ & 41.36 & 41.05 & 1.008 \\
WB & 724.2 & 222.2 & 12.62 & 35.35 & 39.47 & 0.895 \\
UA & 663.9 & 274.9 & 14.49 & 45.22 & 29.54 & 1.531 \\
HA & 729.0 & 197.9 & 17.54 & 46.30 & 43.38 & 1.020 \\
BA & 753.2 & 249.0 & 16.09 & 45.68 & 49.08 & 0.931 \\
LE & 620.8 & 356.8 & 10.49 & 36.62 & 29.1 & 1.258 \\
GJ & 928.8 & 310.1 & 21.99 & 43.12 & 50.26 & 0.858 \\
JW & 704.9 & 226.8 & 23.43 & 37.35 & 40.13 & 0.931 \\
MM & 775.4 & 262.2 & 23.25 & 46.43 & 56.15 & 0.827 \\
\hline Mean & 716.9 & 245.9 & 18.01 & 41.45 & 44.05 & 0.971 \\
S.D. & 83.18 & 48.8 & 4.98 & 5.01 & 9.5 & 0.22 \\
n & 12 & 12 & 11 & 12 & 12 & 12 \\
\hline
\end{tabular}

${ }^{*}$ EGRAC (Erythrocyte Glutathione Reductase Activity Coefficient $)=\left(G R_{+F A D}\right) /\left(G R_{-F A D}\right)$

which the antioxidant enzyme catalase, but not glutathione peroxidase nor superoxide dismutase, was more highly expressed in the resistant than in the parental cells. In addition, the resistant cells had enhanced rate of glutathione (GSH) regeneration due to higher activities of GSH metabolic enzymes, i.e. GSH reductase and gamma-glutamylcysteine synthetase as well as GSH-S-transferase (Sagara et al., 1998). This experiment proved that resistance to oxidative stress potentially leading to apoptosis may be acquired by coordinated changes in the antioxidant defense centration usually constitutes about onefourth of that of alpha (Vatassery et al., 1983a). Mean serum $\alpha$-, and $\gamma$-tocopherol concentrations, as found in 451 healthy human male and female subjects aged 19 to 70 years by Behrens \& Madere (1986), were $8.82 \pm 2.84$ $\mu \mathrm{g} / \mathrm{mL}(20.5 \mu \mathrm{mol} / \mathrm{L})$ and $1.35 \pm 0.70 \mu \mathrm{g} / \mathrm{mL}$ (3.25 $\mu \mathrm{mol} / \mathrm{L})$, respectively. Plasma or serum $\alpha$-tocopherol concentrations of $<11.6,11.6$ 16.2 and $>16.2 \mu \mathrm{mol} / \mathrm{L}$ are normally regarded as indicating deficient, low and acceptable vitamin E status, respectively (Morrissey \& Sheehy, 1999). In this respect all but one our 
centenarians had adequate vitamin $\mathrm{E}$ levels. It is noteworthy to underly that the mean $\alpha$-tocopherol concentration in centenarians was by about $30 \%$ higher $(15.05 \mu \mathrm{g} / \mathrm{mL})$ than in young female adults $(11.59 \mu \mathrm{g} / \mathrm{mL})$ (Tables al., 1983b). A similar trend was observed in our study as the mean $\gamma$-tocopherol level in our centenarians was only about one-third of that regarded as normal ( 0.40 vs $1.35 \mu \mathrm{g} / \mathrm{mL})$ (Behrens \& Madere, 1986). A comment is nec-

Table 5. Vitamin E and vitamin A status and other parameters of the antioxidant defense system in centenarians

\begin{tabular}{|c|c|c|c|c|c|c|c|}
\hline Initials & $\begin{array}{c}\alpha \text {-Tocopherol } \\
(\mathrm{mg} / \mathrm{L})\end{array}$ & $\begin{array}{c}\gamma \text {-Tocopherol } \\
(\mathrm{mg} / \mathrm{L})\end{array}$ & $\begin{array}{l}\text { Retinol } \\
(\mathrm{mg} / \mathrm{L})\end{array}$ & $\begin{array}{c}\text { Se in whole blood } \\
(\mu \mathrm{g} / \mathrm{L})\end{array}$ & $\begin{array}{l}\text { Uric acid } \\
(\mathrm{mg} / \mathrm{dL})\end{array}$ & $\begin{array}{l}\text { Homocysteine } \\
(\mathrm{mg} / \mathrm{L})\end{array}$ & $\begin{array}{c}\mathrm{MDA} \\
(\mu \mathrm{mol} / \mathrm{L})\end{array}$ \\
\hline JN & 20.86 & 0.14 & 0.57 & 40.00 & 4.91 & 1.265 & 1.25 \\
\hline KK & 22.96 & 0.42 & 0.50 & 82.40 & 4.48 & 0.928 & 2.35 \\
\hline PS & $(<0.5)$ & $(<0.02)$ & 0.43 & 38.30 & 4.49 & 1.240 & 2.51 \\
\hline WA & 11.49 & 0.61 & 0.33 & 30.30 & ND & 1.468 & ND \\
\hline WB & 9.80 & 0.25 & 0.29 & 34.60 & 3.87 & 0.765 & 1.64 \\
\hline UA & 11.37 & 0.37 & 0.45 & 21.50 & 6.41 & $(4.862)$ & 2.04 \\
\hline $\mathrm{HA}$ & 11.04 & 0.32 & 0.41 & 27.60 & 3.13 & 0.873 & 1.96 \\
\hline $\mathrm{BA}$ & 22.96 & 0.11 & 0.54 & 39.20 & ND & 1.026 & ND \\
\hline LE & 9.98 & 0.29 & 0.18 & 33.60 & 5.45 & 1.493 & 1.49 \\
\hline GJ & 10.12 & 0.28 & 0.28 & 21.60 & 6.36 & 0.944 & 2.28 \\
\hline JW & ND & ND & ND & 36.70 & 3.89 & ND & 1.96 \\
\hline MM & 19.93 & 0.58 & 0.40 & 41.90 & 4.58 & 0.727 & 1.41 \\
\hline Mean & 15.05 & 0.34 & 0.40 & 37.3 & 4.76 & 1.073 & 1.89 \\
\hline S.D. & 5.79 & 0.16 & 0.12 & 15.7 & 1.06 & 0.277 & 0.42 \\
\hline $\mathrm{n}$ & 10 & 10 & 11 & 12 & 10 & 10 & 10 \\
\hline
\end{tabular}

3 and 5), however the difference was not significant. Our results agree with those of other authors (Elmadfa et al., 1986) who reported increased and age-dependent plasma tocopherol concentration in elderly of 62-98 years of both sexes. Similar were the observations of Paolisso et al. (1998) who found that vitamin $\mathrm{E}$ concentration was more elevated in centenarians than in aged subjects (29 vs 24 $\mu \mathrm{mol} / \mathrm{L}$ ) and those of Hallfrisch et al. (1994) who revealed that older people from a group of 200 women and 231 men aged 20 to 95 years had higher plasma tocopherol levels. Although other authors reported that $\alpha$ - and total tocopherol concentrations did not change significantly with age, they found that plasma $\gamma$-tocopherol decreased significantly with age in patients aged 21 to 91 years (Vatassery et essary on the finding that one of our patients (PS) had very low serum level of vitamin E; a possible cause of such a major deficiency could be fat malabsorption or genetic abnormality in lipoprotein metabolism in this subject, but the true reason of this deficiency cannot be resolved without additional biochemical analyses.

As to mean retinol content it was close to the lower limit of the reference range (0.34-0.75 $\mathrm{mg} / \mathrm{L})$ (Jakubowski et al., 1995), which means that some centenarians (3 persons) had inadequate level of this vitamin. It seems likely that this fact might contribute to sight deterioration recorded in these subjects.

Another low molecular mass antioxidant present in plasma is uric acid. Urate is known to be fast-reacting peroxyl scavenger in the 
plasma, capable of scavenging 2 peroxyl radicals per molecule (Rice-Evans et al., 1991). Urate in normal physiological concentration efficiently protects hemoglobin and erythrocytes against oxidation by ROS and peroxidative damage of membrane lipids. It can also react with singlet oxygen and hydroxyl radicals acting as a potent antioxidant. It should be noted that urate concentrations recorded in the present study were, in all but one case, within the physiological range (3-5.7 $\mathrm{mg} \times \mathrm{dl}^{-1}$ ) (Prencipe et al., 1978). Interestingly, the mean plasma urate concentration in centenarians was significantly higher ( $P<0.05$ by Mann-Whitney U-test) than in young female adults (Tables 3 and 5), which might be interpreted as a positive mechanism enabling better protection of erythrocytes from peroxidative damage (Ames et al., 1981).

The degree of oxidative stress may be approximately evaluated based on plasma concentration of malondialdehyde formed from the breakdown of lipid hydroperoxides and reacting with thiobarbituric acid to give a pink coloured adduct. The reaction is not very specific, but its reliability and specificity may be improved by extraction of the chromogene with n-butanol and by using butylated hydroxytoluene (BHT) as antioxidant preventing autooxidation of lipids, the procedure that we used in our study. Unexpectedly, we found that the degree of oxidative stress was lower in healthy centenarians $(1.89 \pm 0.42 \mu \mathrm{mol} / \mathrm{L})$ as compared to young female subjects $(4.45 \pm$ $1.73 \mu \mathrm{mol} / \mathrm{L}$ ) (Tables 3 and 5). Similar phenomenon was reported by Paolisso et al. (1998) who found that the degree of oxidative stress as measured by levels of thiobarbituric acid reacting substances (TBARS) and lipid hydroperoxides (LPO) was lower in healthy centenarians than in aged subjects. They also reported that plasma vitamin $\mathrm{E}$ concentration and reduced to oxidized glutathione (GSH/ GSSG) ratio were more elevated $(P<0.05$ and $P<0.01$, respectively) in centenarians than in aged subjects.
One of the major causes of death and disability in industrialized nations is atherosclerosis. To some degree atherosclerosis is found in almost all aged subjects, which may suggest that it can be regarded both as a normal aging process and a disease. Among many independent risk factors for atherosclerotic disease one should mention homocysteine (Hcy), which is an intermediate formed during the metabolism of essential sulfur-containing amino acid methionine. It is usually noticed that homocysteine concentration rises progressively with age both in men and women. The age-related rise in plasma Hcy level is explained by a decline in glomerular filtration rate (GFR) in aged patients, therefore, the hyperfiltration occurring in diabetes mellitus may explain the lower than normal mean plasma total homocysteine (tHcy) in diabetic patients (Wollesen et al., 1999). Some authors (e.g. Gottfries et al., 1998) link elevated levels of serum-homocysteine with decline in cognitive function and consider it as an early and sensitive marker for cognitive impairment. Therefore, they suggest that homocysteine may represent a metabolic link between the pathogenesis of atherosclerotic vascular diseases and old-age dementias (Parnetti et al., 1997); Hcy is also considered as being a reliable marker of vitamin $\mathrm{B}_{12}$ and folate deficiency, which is the case frequently reported in demented geriatric patients. However, in our subjects no significant correlation between the Mini-Mental State Examination score and Hcy level was present $(P=0.38, \mathrm{R}$ Spearman $=-0.308$ ), although interesting was our finding that MMSE score correlated significantly $(P<0.05$, R Spearman $=0.705)$ with erythrocyte glutathione reductase activity. Serum total Hcy concentration in our group of centenarians varied from 0.727 to $1.468 \mu \mathrm{g} / \mathrm{ml}$ (Table 5), only in one case (UA) it attained the level of $4.862 \mu \mathrm{g} / \mathrm{ml}$. With except of the latter result the mean serum Hcy concentration was $1.073 \pm 0.277 \mu \mathrm{g} / \mathrm{ml}$, which was within the reference range for an elderly 
population ( 0.958 to $2.092 \mu \mathrm{g} / \mathrm{ml}$, with mean equal $1.404 \mu \mathrm{g} / \mathrm{ml}$ ) (Clarke et al., 1998). It is worthy to stress that among most important risk factors for increased total Hcy concentration are daily lifestyle, namely high protein diet, low folate and vitamin $\mathrm{B}_{12}$ intake, smoking and high coffee consumption (Nygard et al., 1998).

Progression of atherosclerosis is accelarated in diabetes mellitus. High glucose may exert its deletorious effect by pathogenic mechanisms involving enzymatic metabolism of glucose as well as non-enzymatic pathways. One such mechanism is the non-enzymic glycation of intra- and extracellular proteins, lipoproteins and possibly also nucleic acids. Advanced glycation end products are known to accumulate during aging and they might contribute to the development of micro- and macroangiopathy (Bierhaus et al., 1998). Enhanced glycation may have direct effects (e.g. causing changes in the physico-chemical properties of proteins or stimulating AGEs receptor-mediated pathologic changes in gene expression) or may amplify the effects of oxidative stress on lipoproteins, mainly low density lipoproteins (LDL) thus increasing chemotactic property of LDL. Glycation is also known to induce simultaneous losses of antigenicity and inactivation of antioxidant enzymes: catalase and superoxide dismutase (Yan \& Harding, 1997). In our group of centenarians about $70 \%$ of patients suffered from advanced retinopathy, which was the main cause of disability. This might be interpreted as being indicative of severe microvascular complications. It is very difficult to interprete the results of glucose, insulin and AGEs concentration. Of the fifteen centenarians in 3 subjects a minor and in one case a major hyperglycemia were found, but in all these cases the insulin level was within the reference range. In two patients the insulin level was below the reference range, however glucose concentration was normal; in two other subjects the insulin level exceeded the upper limit of the reference range, but as previously, the glucose level was normal. Instability in insulin level, the phenomenon usually observed in elderly patients, might be explained in terms of a diminished insulin uptake by liver in response to a lower rate of insulin synthesis by pancreas, which seems to be typical in advanced age. Anyway, it seems very unlikely that subjects suffering from diabetes mellitus could attain very old age.

As to the serum levels of AGEs in our group of patients they showed high variability and ranged from 3 to about $50 \mathrm{U} / \mathrm{mL}$. Those not exceeding $12-15 \mathrm{U} / \mathrm{ml}$ might be considered as normal as it was evidenced by Papanastasiou et al. (1994) in healthy adults. Only 6 of 14 centenarians had low and moderate AGEs levels; in remaining eigth subjects the levels were elevated with maximum of about $50 \mathrm{U} / \mathrm{ml}$. It is interesting to find out that subjects with elevated Hcy and AGEs had very low MMSE score which was indicative of higher degree of dementia, however the low number of subjects examined within the frame of this project and a lack of significant correlation between MMSE and AGEs $(P=0.22, \mathrm{R}$ Spearman $=$ -0.35 ) do not qualify us to make any generalizations.

In conclusion, our preliminary study revealed that among the independent factors contributing to human longevity are increased capacity for antioxidant defense mainly due to relatively high activity of antioxidant enzymes: glutathione reductase and catalase acting in concert with $\alpha$-tocopherol as low molecular masas antioxidant.

\section{R E F E R E N C E S}

Aebi, H. (1974) Catalase; in: Methods of Enzymatic Analysis (Bergmayer, H.U., ed.) pp. 673-683.

Ames, B.N., Cathart, R., Schwiers, E. \& Hochstein, P. (1981) Uric acid provides an antioxidant defense in humans against oxidantand radical-caused aging and cancer: $\mathrm{A}$ hypothesis. Proc. Natl. Acad. Sci. U.S.A. 78, 6858-6862. 
Behrens, W.A. \& Madere, R. (1986) Alpha- and gamma-tocopherol concentrations in human serum. J. Am. Coll. Nutr. 5, 91-96.

Bierhaus, A., Ziegler, R. \& Nawroth, P.P. (1998) Molecular mechanisms of diabetic angiopathy - clues for innovative therapeutic interventions. Hormone Res. 50 (S1), 1-5.

Buege, J.A. \& Aust, S.D. (1978) Microsomal lipid peroxidation. Methods Enzymol. 52, 302-310.

Casesnoves, A., Mauri, M., Dominguez, J.R., Alfayate, R. \& Pico, A.M. (1998) Influence of anti-insulin antibodies on insulin immunoassays of the autoimmune insuline syndrome. Am. Clin. Biochem. 35, 768-774.

Cao, G., Booth, S.L., Sadowski, J.A. \& Prior, R.L. (1998) Increases in human plasma antioxidant capacity after consumption of controlled diets high in fruit and vegetables. Am. J.Clin. Nutr. 68, 1081-1087.

Caprari, P., Scuteri, A., Salvati, A.M., Bauco, C., Cantafora, A., Masella, R., Modesti, D., Tarzia, A. \& Marigliano, V. (1999) Aging and red blood cell membrane: A study of centenarians. Exp. Gerontol. 34, 47-57.

Clarke, R., Woodhouse, P., Ulvik, A., Frost, C., Sherliker, P., Refsum, H., Ueland, P.M. \& Khaw, K.T. (1998) Variability and determinants of total homocysteine concentrations in plasma in an elderly population. Clin. Chem. 44, 102-107.

Cobler, J.L., Akiyama, T. \& Murphy, G.W. (1989) Permanent pacemakers in centenarians, $J$. Am. Geriatr. Soc. 37, 753-756.

Cutler, R.G. (1985) Peroxide-producing potential of tissues: Inverse correlation with longevity of mammalian species. Proc. Natl. Acad. Sci. U.S.A. 82, 4798-4802.

Danch, A. \& Dróżdż, M. (1996) A simplified technique of fluorometric selenium assay in biological material. Diagn. Lab. 32, 529-534.

Elmadfa, I., Both-Bedenbender, N., Sierakowski, B. \& Steinhagen-Thiessen, E. (1986) Significance of vitamin $\mathrm{E}$ in aging. Z. Gerontol. 19, 206-214.
Fielding, R.A. \& Meydani, M. (1997) Exercise, free radical generation, and aging. Aging (Milano) 9, 12-18.

Flohe, L. \& Gunzler, W.A. (1984) Assays of glutathione peroxidase. Methods Enzymol. 105, 114-120.

Franceschi, C., Monti, D., Scarfi, M.R., Zeni, O., Temperani, P., Emilia, G., Sansoni, P., Lioi, M.B., Troiano, L. \& Agnesini, C. (1992) Genomic instability and aging. Studies in centenarians (successful aging) and in patients with Down's syndrome (accelerated aging). Ann. N.Y. Acad. Sci. 663, 4-16.

Glatzle, D., Körner, W.F., Christeller, S. \& Wiss, O. (1970) Method for the detection of a biochemical riboflavin deficiency. Stimulation of $\mathrm{NADPH}_{2}$-dependent glutathione reductase from human erythrocytes by FAD in vitro. Investigations on the vitamin $B_{2}$ status in healthy people and geriatric patients. Int. $Z$. Vitaminforsch. 40, 166-183.

Gottfries, C.G., Lehman, W. \& Regland, B. (1998) Early diagnosis of cognitive impairment in the elderly with the focus on Alzheimer's disease. J. Neural. Transm. 105, 773-786.

Hallfrisch, J., Muller, D.C. \& Singh, V.N. (1994) Vitamin $\mathrm{A}$ and $\mathrm{E}$ intakes, and plasma concentrations of retinol, beta-carotene, and alpha-tocopherol in men and women of the Baltimore Longitudinal Study of Aging. Am. J. Clin. Nutrit. 60, 176-182.

Harman, D. (1992) Free radical theory of aging. Mutat. Res. 275, 257-266.

Jakubowski, Z., Kabata, J., Kalinowski, L., Szczepańska-Konkel, M. \& Angielski, S. (1995) Laboratory analyses in everyday practice, reference values and their interpretation, MAKMed, p. 343, Gdańsk (in Polish).

Lombeck, I., Kasperek, K., Harbisch, H.D., Feinendegen, L.E. \& Bremer, H.J. (1977) The selenium state of healthy children. I. Serum selenium concentrations at different ages; Activity of glutathione peroxidase of erythrocytes at different ages; Selenium content of food of infants. Eur. J. Pediatr. 125, 81-88. 
Lopez-Torres, M., Perez-Campo, R., Rojas, C., Cadenas, S. \& Barja, G. (1993) Simultaneous induction of SOD, glutathione reductase, GSH, and ascorbate in liver and kidney correlates with survival during aging. Free Radical Biol. Med. 15, 133-142.

Maulik, N., Yoshida, T. \& Das, D.K. (1998) Oxidative stress developed during the reperfusion of ischemic myocardium induces apoptosis. Free Radical Biol. Med. 24, 869-875.

Morrissey, P.A. \& Sheehy, P.J. (1999) Optimal nutrition: Vitamin E. Proc. Nutr. Soc. 58, 459-468.

Nygard, O., Refsum, H., Ueland, P.M. \& Vollset, S.E. (1998) Major lifestyle determinants of plasma total homocysteine distribution: The hordaland homocysteine study. Am. J. Clin. Nutr. 67, 263-270.

Olivieri, O., Stanzial, A., Girelli, D., Trevisan, M.D., Guarini, P., Terzi, M., Caffi, S., Fontana, F., Casaril, M., Ferrari, S. \& Corrocher, R. (1994) Selenium status, fatty acids, vitamin A and E, and aging: The Nove study. Am. J. Clin. Nutr. 60, 510-517.

Parnetti, L., Bottiglieri, T. \& Lowenthal, D. (1997) Role of homocysteine in age-related vascular and non-vascular diseases. Aging (Milano) 9, 241-257.

Paolisso, G., Tagliamonte, M.R, Rizzo, M.R, Manzella, D., Gambardella, A., Varicchio, M. (1998) Oxidative stress and advancing age: Results in healthy centenarians J. Am. Geriatr. Soc. 46, 833-838.

Papanastasiou, P., Grass, L., Rodela, H., Patrikarea, A., Oreopoulos, D.G. \& Diamandis, E. (1994) Immunological quantification of advanced glycosylation end-products in the serum of patients on hemodialysis or CAPD. Kidney Int. 46, 216-222.

Prencipe, L., Fossati, P. \& Vanetti, G. (1978) Enzymatic determination of uric aid in serum with the trinder reaction. Quad. Sclavo. Diagn. 15, 382-394.

Rice-Evans, C.A., Diplock, A.T. \& Symons, M.C.R. (1991) Techniques in Free Radical Research, pp. 47-50, Elsevier, Amsterdam.
Roberts, W.C. (1998) The heart at necropsy in centenarians. Am. J. Cardiol. 81, 1224-1225.

Rodriguez-Martinez, M.A. \& Ruiz-Torres, A. (1992) Homeostasis between lipid peroxidation and antioxidant enzyme activities in healthy human aging. Mech. Ageing Dev. 66, 213-222.

Rodriguez, M.L., Smart, D., McCusker, C.A., Lamont, J.V., FitzGerald, S.P., Temml, C. \& Lapin, A. (1996) Total antioxidant status (TAS) and glutathione reductase (GR) in geriatric patients. VIII Biennal Meeting for the International Society for Free Radical Research, Spain.

Sagara, Y., Dargusch, R., Chambers, D., Davis, J., Schubert, D. \& Maher, P. (1998) Cellular mechanisms of resistance to chronic oxidative stress. Free Radical Biol. Med. 24, 1375-1389.

Sobczak, A., Skop, B. \& Kula, B. (1999) Simultaneous determination of serum retinol and alpha- and gamma-tocopherol levels in type II diabetic patients using high-performance liquid chromatography with fluorescence detection. J. Chromatog. B. Biomed. Sci. Appl. 730, 265-271.

Sohal, R.S. \& Orr, W.C. (1992) Relationship between antioxidants, prooxidants, and the aging process. Ann. N. Y. Acad. Sci.663, 73-74.

Toh, S.Y., Thompson, G.W. \& Basu, T.K. (1994) Riboflavin status of the elderly: Dietary intake and FAD-stimulationg effect on erythrocyte glutathione reductase coefficients. Eur. J. Clin. Nutr. 48, 654-659.

Vatassery, G.T., Krezowski, A.M. \& Eckfeldt, J.H. (1983a) Vitamin E concentrations in human blood plasma and platelets. Am. J. Clin. Nutr. 37, 1020-1024.

Vatassery, G.T., Johnson, G.J. \& Krezowski, A.M. (1983b) Changes in vitamin $\mathrm{E}$ concentrations in human plasma and platelets with age. $J$. Am. Coll. Nutr. 2, 369-375.

Warner, H.R. (1994) Superoxide dismutase, aging, and degenerative disease. Free Radical Biol. Med. 17, 249-258.

Wollesen, F., Brattstrom, L., Refsum, H., Ueland, P.M., Berglund, L. \& Berbe, C. (1999) Plasma total homocysteine and cysteine in relation to 
glomerular filtration rate in diabetes mellitus. Kidney Int. 55, 1028-1035.

Yan, H. \& Harding, J.J. (1997) Glycation-induced inactivation and loss of antigenicity of catalase and superoxide dismutase. Biochem. J. 328, 599-605.

Young, P.B., Molloy, A.M., Scott, J.M. \& Kennedy, D.G. (1994) A rapid high performance liquid chromatographic method for determination of homocysteine in porcine tissue. J. Liquid Chromat. 17, 3553-3561.

Yu, B.P. (1996) Aging and oxidative stress: Modulation by dietary restriction. Free Radical Biol. Med. 21, 651-668. 